\title{
Changing Hostile Beliefs towards Women through Partner Abuse Intervention Programs
}

\author{
Diane Zosky \\ School of Social Work, Illinois State University, Normal, IL, USA \\ Email: dlzosky@ilstu.edu \\ Received 3 January 2016; accepted 18 February 2016; published 24 February 2016 \\ Copyright (c) 2016 by author and Scientific Research Publishing Inc. \\ This work is licensed under the Creative Commons Attribution International License (CC BY). \\ http://creativecommons.org/licenses/by/4.0/

(c) (i) Open Access

\section{Abstract}

This research project examined hostile beliefs towards women held by men who completed a Duluth Model partner violence intervention program. Changes in beliefs are foundational to change in the cessation of violence within the Duluth model. Hostile beliefs towards women establish a context for objectification and suspicion of women, and justification for violence. Although there was not a significant reduction in hostility scores, there was a significant reduction in aggression scores. Hostility scores were significantly correlated with the aggression scores indicating encouraging results that partner abuse intervention programs may influence the reduction of hostile beliefs towards women and thus may impact perpetration of violence.

\section{Keywords}

Hostility, Partner Abuse Intervention, Aggression

\section{Introduction}

In the past thirty years domestic violence has emerged as a significant social issue for research and theory development. A variety of treatment programs for male perpetrators have developed over the past several years [1]. Many programs converge around gender-based, cognitive-behavioral methods which address misogynist and patriarchal beliefs, anger awareness, skill-building in communication and anger re-direction, and confrontation of the consequences of abusive behavior. The Duluth model is the most common intervention program for male perpetrators of intimate partner violence [1] [2].

Outcome measurements thus far have been mixed. Several published reviews of outcome measurements from 
single site evaluations have reported success rates between $60 \%$ and $80 \%$ [3]-[6]. Deeper meta-analyses, however, have reported quite small effect sizes [7] [8]. Babcock et al. [7] concluded that a woman was only 5\% less likely to be re-assaulted by her partner after intervention as compared to if her partner was only arrested and received no intervention. Feder and Wilson [8] reported that the effect size from their meta-analysis was non-existent.

Methodological challenges contribute to difficulty in measuring success for intimate partner violence intervention programs. Most studies operationalize successful intervention as the cessation of violence. Although the cessation of violence is a laudable longitudinal benchmark of success, tracking of this outcome becomes a conundrum fraught with methodological and safety concerns. Tracking outcome success by arrest records seems to be inaccurate that the majority of domestic violence never comes to the attention of the law enforcement system. The veracity of data collected regarding cessation of violence from the perpetrator seems to be dubious for obvious reasons. The victim, who could have the best report on the status of power and control tactics and violence, may have her safety in jeopardy if she provides follow-up information on her former batterer. Additionally the low response rate and high mobility of this population increase the concern for mortality threat to validity.

Measurement of intermediate outcomes, therefore, may be a good, partial alternative to the measurement of long-term outcomes of violence cessation. The pre and post measurement of various characteristics in batterers that are thought to contribute to violence may be seen as intermediate outcome data that hopefully translates into long-term outcomes of violence cessation. Hostility is one obvious variable that has been examined with domestically violent men [9]-[11]. Hostility is at least a mechanism for power and control and at worst may be precursors to violence.

\subsection{Definition of Hostility}

Although the emotions of anger and hostility are often used interchangeably in empirical studies regarding domestic violence, they are related but separate experiences [12]. Both anger and hostility seem to be multi-dimensional and complex emotional experiences with many permutations. Anger is often defined as a subjective feeling state with corresponding physiological responses of agitated arousal [13]. Anger may be expressed directly and overtly, or indirectly and in a passive-aggressive manner. The result may include emotional abuse, verbal abuse, and even physical violence [14].

Hostility is often defined as an attitudinal or cognitive construct that involves dislike and negative evaluations of another [15]. Hostility can be dynamically bi-directional. While hostility describes negative feelings one holds of another, hostile attributional bias is defined as the belief that another's actions are born from hostile intentions towards oneself [16]. Hostility as attitude or cognition may precede angry feelings which may in turn precede aggressive behavior [12] [17]. Anger and hostility appear to be distinct, yet related phenomenon on a continuum that may progress to violence.

\subsection{Origin of Hostility}

A hostile world view is thought to develop in childhood through developmental ruptures [18]. Children who experience neglect, inconsistent care, abuse, or witness their parents' violence experience attachment disruptions from the traumatic exposure. An instinctual response to adapt to such traumatic experiences is to exist in a state of hypervigilance. Children who engage their world through hyper-arousal may be prone to misinterpret neutral or positive behavior as threat [19]. As an adaptive aspect of survival instinct, children may develop social information processing styles that interpret ambiguous cues as hostile in order to ensure safety [16].

\subsection{The Relationship of Hostility to Intimate Partner Violence}

There have been several studies conducted that examined the relationship of hostility to domestic violence. Maiuro, Cahn, Vitaliano, Wagner and Zegree [11] compared a group of domestically violent men, a group of men who were assaultive only outside the family, a group who had exhibited violence both inside the family and outside the family, and a nonviolent comparison group on scores relating to anger and hostility. All three of the violent groups had significantly higher scores on the Buss Durkee Hostility Inventory Overt and Covert subfactors than the non-violent comparison group. They also scored significantly higher on the Assault, Indirect, Irritability, Resentment, and Suspicion subscales. Use of the Hostility and Direction of Hostility Questionnaire 
demonstrated the violent groups were significantly higher on the Extrapunitive, Acting out Hostility, and the Criticize Others subfactors.

A similar study was completed one year later by Maiuro, O’Sullivan, Michael and Vitaliano [20] who used the same instruments to measure anger and hostility between a group of assaultive men and suicidal men. Both the assaultive men and the suicidal men scored significantly higher on scores for anger and hostility than the non-violent comparison group. The suicidal men scored higher on the Hostility and Direction of Hostility Questionnaire Intropunitive subfactor and the assaultive group scored higher on the Buss Durkee Hostility Inventory Overt, Assault, and Verbal subscales. This study did replicate the previous study in that assaultive men scored higher on hostility and anger. It was an interesting finding that suicidal men also had elevated scores, but the direction of anger and hostility was internal for suicidal men and external for assaultive men.

Barnett, Fagan and Booker [21] compared five groups of men on hostility and stressors. The groups included maritally violent only and uncounseled men, maritally violent only and counseled men, men who had primarily been violent outside relationships, maritally distressed non-violent men, and maritally satisfied non-violent men. The maritally violent men scored significantly higher on hostility than any other group. Interestingly, partner stress also rated the highest as a stressor for the violent men. These results indicate a volatile situation for men who have been indicated for domestic violence, in which stressful interactions with their partner are correlated with chronically hostile dispositions.

Hershorn and Rosenbaum [22] examined abusive men regarding overcontrolling hostility versus undercontrolling hostility. The over-controlled hostility group of men had strong inhibitions of angry and aggressive feelings and had restricted avenues for the display of these emotions. The under-controlled hostility group of men had few controls on the expression of anger and aggression. The authors used the Overcontrolled Hostility Scale [23] to distinguish the two groups. Domestically violent men who were over-controlled in their hostility were more severely violent to their partners than the under-controlled men. The men in the under-controlled group were more frequently violent and more likely to be violent to others outside of the partnership. Undercontrolled batterers were more likely to have witnessed violence between their parents and over-controlled batterers were more likely to have experienced maternal rejection. The authors suggest that the over-controlled batterers were raised in a family where it was anxiety provoking to display anger. Anger is therefore, inhibited, however, once it is released it has accumulated to a disproportionate degree. Under-controlled batterers were thought to have been reared in a family where models were available that demonstrated little control over anger and hostile feelings.

Boyle and Vivian [24] distinguished between generalized anger/hostility and spouse specific anger/hostility scores in non-violent community men, a non-violent group of men from a clinical sample, moderately violent men from a clinical sample, and severely violent men from a clinical sample. The authors found that all of the clinical samples reported higher levels of generalized and spouse specific hostility and anger. Severely violent men reported higher levels of spouse specific hostility than non-violent men. Overall, generalized anger and hostility were not unique predictors of men's violence towards their partners.

Maiuro, Cahn and Vitaliano [25] found an interesting connection between hostility and assertion with domestically violent men. The authors defined assertiveness as both the ability to refuse a demand or request and the ability to initiate a request. They compared assertiveness skills of domestically violent men and a comparison group of non-violent men. The groups did not demonstrate a significant difference regarding the ability to assertively refuse a request. There was, however, a difference between the groups regarding their ability to initiate requests. The domestically violent men had significantly more problems in expressing their wants and needs in assertive and positive methods. The violent men also rated higher on hostility scores. The authors speculate that social skills deficits which hinder the man's ability to initiate a request for needs or wants increase his hostility at not having the needs magically met.

Kachadourian, Homish, Quigley and Leonard [26] examined the role of hostility in alcohol use and intimate partner violence. The authors found an interaction between dispositional hostility and high consumption of alcohol for both men and women. For those who scored higher in hostility, heavy drinking predicted increased intimate partner violence. There appeared to be no relationship between alcohol consumption and increased violence for those who scored low in dispositional hostility. This suggests that hostility may play a mediating role between alcohol consumption and violence.

While several researchers have documented dispositional hostility with men who perpetrate intimate partner violence, these men also have an increased hostile attributional bias [16] [27] [28]. Men who perpetrate intimate 
partner violence frequently ascribe negative or hostile intent to their partner's behavior. This may be both a catalyst for aggression and/or a defense of aggression. Men who misinterpret their partners' intent as hostile or threatening may be more likely to respond with violence. Men who commit violence may also be quick to attribute hostility to their partners after the violent episode to justify their actions [10]. A tendency to invoke hostile attributional bias combined with dispositional hostility creates a volatile, bi-directional dynamic in men who are violent as they are hostile while they also perceive their partners as hostile.

Hostility towards women is considered one of the five proximal variables used by Holtzworth-Munroe and Stuart [29] as they developed their tripartite typology of perpetrators of domestic violence. The authors developed a model to classify perpetrators into three categories of family only batterers, dysphoric/borderline batterers, and generally violent/antisocial batterers. The authors propose that the characteristic of holding hostile beliefs towards women was one of the distinguishing variables of men in the dysphoric/borderline and generally violent/antisocial classification.

The most common perpetrator intervention program, The Duluth Model, considers the elimination of hostile beliefs towards women as the fundamental change effort to end violence [30]. The Duluth Model proposes that men who perpetrate intimate partner violence must first examine their beliefs about women before they can examine their behavior. Hostile beliefs about women often determine the context that has supported men's justification of violent behavior. If intervention is focused on changing the context or belief, men are open to choosing a different behavioral response.

The literature is replete with research that examines the role of hostility in domestic violence. As hostility is defined as an attitudinal construct it seems to be an attitude based on beliefs. If one holds misogynist and patriarchal beliefs, it seems reasonable that one would experience hostility to women when these beliefs meet resistance or challenge. Changes in measures of hostility may be a representative proxy for changes in misogynist or patriarchal beliefs structures within an intimate relationship. If a male batterer no longer believes he has the right to power and control over a female partner, there would be less likelihood for hostility and anger to manifest as a mechanism for power and control. This study seeks to identify changes in hostility in men participating in a batterer intervention program. Changes in hostility may be a valid intermediate measure of success towards the ultimate goal of violence cessation.

This study is guided by four hypotheses as follows:

Ho 1: There will be a significant decrease in hostile beliefs about women for men who complete a Partner Abuse Intervention Program.

Ho.2: There will be a significant reduction in aggression scores for men who complete the Partner Abuse Intervention Program.

Ho.3: There will be a correlation between hostile beliefs about women and aggression after completion of a Partner Abuse Intervention Program with lower hostility scores being correlated with lower aggression scores.

Ho4: Hostile beliefs about women scores will significantly predict aggression scores.

\section{Methods}

\subsection{Sample}

The sample in this study consisted of 92 men who were referred to and completed a batterer intervention program in a mid-west, urban community over a two year period. There were 187 men who began the program, but slightly less than half persisted. All of the participants were mandated to attend the 26-week program as a condition of their sentencing. The majority of men were white with less than a fifth identified as African American and a small percentage of men identified as Latino (Table 1). The mean age of participants who completed was approximately 33 years old $(M=32.59, S D=9.35)$ with the youngest being 18 and the oldest being 60 years old. The mean age of participants that included non-completers was not significantly different $(M=32.77, S D=$ 9.32). The majority of the participants were either married or cohabitating with their partner, with approximately one quarter either separated or divorced, and the smallest number identified as single (Table 2). The index victim was equally distributed with half being their current partner and half being a former partner.

\subsection{Instrumentation}

Hostility was measured with the Hostility Towards Women Scale [26]. This self-report scale is designed to 
Table 1. Race from participants who began as compared to those who completed.

\begin{tabular}{ccc}
\hline & Race of participants & \\
\hline Race & Percentage at beginning & Percentage at completion \\
\hline White & $74.8 \%$ & $72.2 \%$ \\
African American & $20.9 \%$ & $20.2 \%$ \\
Latino & $4.3 \%$ & $5.6 \%$ \\
\hline
\end{tabular}

Table 2. Marital status of participants who began as compared to those who completed.

\begin{tabular}{ccc}
\hline & Marital status & \\
\hline Status & Percentage at beginning & Percentage at completion \\
\hline Married & $25.2 \%$ & $26.4 \%$ \\
Cohabitating & $29.7 \%$ & $30.2 \%$ \\
Divorced & $17.1 \%$ & $15.1 \%$ \\
Separated & $9.9 \%$ & $11.3 \%$ \\
Single & $18.0 \%$ & $17.0 \%$ \\
\hline
\end{tabular}

measure trait hostility that men have towards women. It is comprised of 30 statements that are endorsed as true or false. Higher scores indicate higher hostility. The instrument is reported as having reliability of 0.87 [31]. Marshall and Moulden [32] reported that higher scores on the HTW scale were related to lack of empathy for victims by male sexual assault perpetrators.

Aggression was measured with the Aggression Questionnaire [33]. The Aggression Questionnaire is a 29item questionnaire. Respondents use a five-point Likert rating to respond to each statement with one equaling "extremely uncharacteristic of me” to five equaling “extremely characteristic of me”. The questionnaire has four subscales that measure physical violence, verbal violence, anger, and hostility in addition to a total score. Scores are derived by summing the items in the subscale or for the entire scale. Scores range from 29 - 145 for the total scale with higher scores indicating a greater likelihood of aggression. The internal consistency of the scale is strong with the alpha coefficients of 0.85 for physical aggression, 0.72 for verbal aggression, 0.83 for anger, and 0.77 for the hostility subscale. The alpha coefficient for the total scale is 0.89 . The scale also performs well with test-retest reliability rated as 0.80 for the total score.

\subsection{Data Collection and Analysis}

Participants in the study were all mandated to complete a protocol-approved partner abuse intervention program. Most of the participants were required to attend as a condition of probation from a domestic violence charge. Some men were referred by a child welfare judge as part of the treatment plan for an indicated case of child abuse or neglect. In these situations, domestic violence was one of the identified issues that the parents were required to address for resolution of the child welfare intervention. The program was a 26-week group course that met for two hours each week. The curriculum was based on the Duluth Model and groups were closed. Once the groups convened, no new participants were added. All groups were gender-specific and all participants in this study were male.

Each participant was screened for participation in an intake interview. The interview gathered basic assessment information, explained the rules of the program, explained the requirement of victim notification if there were threats, explained the probation reporting process, acquired signed releases of information for probation and the perpetrator's victim, acquired consent for participation, and generally oriented the men to the program. After a potential participant completed the intake interview, he was enrolled in the next available group.

As the groups were a closed format, all participants started the group at the same meeting. Group members completed the pre-test instruments on the first day of group. The pre-test instruments were used by the program for quality assurance and to provide accountability on outcome measurements for funding sources and accrediting bodies. The pre-test measures were gathered prior to any content from the curriculum was delivered and were a base-line assessment of participants prior to intervention. The same measures were used as post-tests at 
the end of the program at the last group meeting. All instruments were scored and entered into SPSS for analysis. A paired-samples $t$ test was conducted to examine for change in hostility and aggression from time one to time two. The alpha level was set at the conventional 0.05 level. Pearson's correlation coefficient analysis was conducted to examine the relationship between the variables of hostility and aggression and hostility and age. Linear regression was conducted to discern how hostility contributed to aggression. One-way analysis of variance was conducted to examine the difference in hostility score with race and marital status.

\section{Results}

The first hypothesis was not supported by the data. Despite a reduction in scores measuring hostility to women from the pre-test period $(M=11.46)$ to the post-test period $(M=10.15)$, the difference was not statistically significant ( $p=0.203$ ) (Table 3). The effect size using Cohen's $d$ using the within-subjects correction was 0.172. The second hypothesis was supported in that there was a significant reduction in aggression scores from the pre-test period $(M=70.64)$ to the post-test measurement $(M=64.02)$. The effect size using Cohen's $d$ using the within-subjects correction was 0.372 .

Demographic variables such as age, race, and marital status did not seem to influence hostility towards women or aggression scores. There was no significant difference in hostility towards women post-test scores by race $[\mathrm{F}(53)=0.546, p=0.582]$ or marital status [F (52) $=1.27, p=0.292]$. There was no significant correlation with age $(p=0.308)$. There was also no significant difference in the total aggression post-test scores by race [F (53) $=0.989, p=0.383$ ] or marital status [ $\mathrm{F}(52)=1.50, p=0.227]$. There was no significant correlation aggression post-test scores and age $(p=0.697)$.

The third hypothesis was supported by the data. Measurement of hostility was significantly and moderately correlated with the overall measurement of aggression at the end of intervention with the partner abuse program. When the subscales were teased out, hostility was significantly correlated with each subscale with the exception of verbal aggression. It seems logical that the subscale of hostility on the AQ would correlate significantly with the HTW scale, but the moderate level of correlation would indicate that the two scales are measuring hostility slightly differently (Table 4).

The fourth hypothesis was also supported by the data. Linear regression analysis demonstrated that there is a significant relationship between hostility and aggression with hostility comprising nearly $15 \%$ of the variance in aggression (Table 5).

\section{Discussion}

The results from this study indicate positive change in men who receive treatment from a partner abuse intervention program in a group modality. Although the change in the Hostility Towards Women scale was not

Table 3. Comparison of Mean Scores for Hostility and Aggression.

\begin{tabular}{ccccc} 
& Pre-test & Post-test & $t$ statistic & $d f$ \\
\hline HTW & 11.46 & 10.15 & 1.28 & 75 \\
AQ & 70.64 & 64.02 & 2.85 & $44^{*}$ \\
\hline
\end{tabular}

${ }^{*} p=0.007$.

Table 4. Correlation coefficient for hostility and aggression.

\begin{tabular}{|c|c|c|c|c|c|}
\hline & Tot. Aggression & Physical & Verbal & Anger & Hostility \\
\hline \multirow{2}{*}{ Hostility } & $r(61)=0.381$ & $r(61)=-0.249$ & $r(61)=0.058$ & $r(61)=-0.371$ & $r(61)=-0.432$ \\
\hline & $p=0.002$ & $p=0.05$ & $p=0.65$ & $p=0.003$ & $\mathrm{p}=0.001$ \\
\hline
\end{tabular}

Table 5. Regression analysis of hostility with aggression.

\begin{tabular}{ccccc}
\hline Variable & $B$ & $S E B$ & $\beta$ \\
Hostility & 0.970 & 0.307 & 3.81 \\
\hline
\end{tabular}

$p=0.002$. 
statistically significant, the change did indicate a reduction in hostility from the start of the program to the end. The significant reduction in the aggression scores from pre-test to post-test may be a strong indication that partner abuse intervention programs decrease a participant's likelihood for aggression. Although there was not a significant reduction in hostility scores on the Hostility Towards Women scale, the fact that it correlates significantly with the Aggression Questionnaire, and indeed accounts for approximately $15 \%$ of the variance of aggression, may indicate that a decrease in hostility parallels the statistically significant reduction in aggression.

The significant correlational data between the scores on the Hostility Towards Women Scale and the physical aggression subscale from the Aggression Questionnaire may be a positive indication that as perpetrators are less hostile, they are less likely to engage in physical aggression. The significant correlational relationship between the scores on the Hostility Towards Women Scale and the anger subscale of the Aggression Questionnaire also may indicate that less hostility indicates less anger, which may preclude a situation advancing to the use of aggression.

\section{Limitations}

The results from this study, though positive, must be evaluated with caution due to some limitations. Although the demographic characteristics were not considerably different for the program completers versus those who began and did not persist, there may have been other characteristics not measured that would have indicated the completing group as different from those who did not persist. Additionally, the results of this study must be considered as exploratory, not explanatory because there was no way to control for variables that may have influenced hostility towards women and aggression.

Although the construct of hostility is part of the total Aggression Questionnaire, it seems that the items on both instruments are tapping into different contexts of hostility. The Hostility Towards Women Scale [31] includes 30 items that all relate to the respondents' attitudes and relationships specifically to women. The items on the Aggression Questionnaire [33] that comprise the hostility subscale are gender-neutral questions regarding people in general. This may account for the correlational data that indicates a significant but only moderate correlation between the two instruments.

\section{Implications}

Reduction in hostility towards women may be an important precursor to the cessation of violence. As men alter their beliefs about women and their right to power and control over partners, there may be less potential for conflict to escalate to violence in order to maintain a superior status.

Changing beliefs is foundational to the cessation of violence within the Duluth model of intervention for perpetrators of intimate partner violence [30]. The curriculum is built on the premise that in order to change violent behaviors, privileged beliefs of patriarchy must be challenged. Without a change in beliefs that support egalitarian status in relationships, behavioral change for non-violence is difficult to integrate and sustain. If men feel entitled to have power and control over women, justification for violence is defensible to maintain the privileged position.

Hostile beliefs towards women are central beliefs that support patriarchy and power and control. Beliefs about women that are denigrating foster an environment that can easily lead to objectification, suspicion, and justification for violence. Holding hostile beliefs about another seems to inherently preclude the possibility of an egalitarian relationship.

Several techniques, practices, and assumptions with the Duluth Curriculum are aimed at challenging hostile beliefs towards and about women. Indeed the first of five objectives for the curriculum is "to assist the participant to understand that his acts of violence are a means of controlling his partner's actions, thoughts, and feelings by examining the intent of his acts of abuse and the belief system from which he operates" [34].

A central method to provoke men to examine their beliefs about women is the use of control logs [30]. The Duluth Curriculum is built on ten themes and participants complete one control log for each theme. Control logs require the perpetrator to respond to seven reflective inquiries regarding their perpetration of violence including: 1) identification of their abusive behavior, 2) identification of their intentions and beliefs, 3) identification of their feelings and their partner's feelings at the time, 4) identification of how they used minimization, denial, and blame to obfuscate their responsibility, 5) identification of the impact of the violence on the perpetrator, the primary victim, and secondary victims, 6 ) identification of how past violence affected the identified violent be- 
havior, and 7) identification of a non-controlling alternative response. The first step with a control log requires participants to identify an abusive action based on the theme. The next critical step towards change is developing an understanding of the intention of the behavior and their beliefs about women that supported their justification for the intention and subsequent action. The step of examination of beliefs is fundamental to the exploration of behavioral change.

A second process used in the Duluth Curriculum is the use of videos of actors portraying interactions to highlight each of the themes. The videos are processed in the group allowing the participants to identify the mechanisms of power and control and to identify the beliefs that supported the action of power and control.

Although this was not an explanatory research project, the results are encouraging regarding effectiveness outcomes for perpetrator intervention programs. As the foundation for change through intervention based on the Duluth Curriculum is changed beliefs, it would seem that any reduction in hostile beliefs towards women would support behavioral change that is non-violent. Although there was not a significant reduction in hostile beliefs towards women, there was a significant reduction in the measurement of aggression. As the hostile beliefs were significantly correlated to aggression, there is some encouraging support that men who complete the program with a decrease in aggression may have also changed their hostile beliefs.

The results from this study indicate that it is important to emphasize change in all forms of power and control dynamics, not just the most severe form of physical violence. Although complete cessation of physical violence is the primary outcome sought for batterer intervention programs, reduction in all aspects of power and control is the only way to achieve relationships based on a model of equality. Changed behavior that manifest in the reduction of hostility is progression in the direction of equality.

\section{References}

[1] Day, A., Chung, B., O’Leary, P. and Carson, E. (2009) Programs for Men who Perpetrate Domestic Violence: An Examination of the Issues Underlying the Effectiveness of Intervention Programs. Journal of Family Violence, 24, 203-212. http://dx.doi.org/10.1007/s10896-008-9221-4

[2] Jackson, S. (2003) Analyzing the Studies. In Jackson, S., Feder, L., Forde, D.R., Davis, R.C., Maxwell, C.D. and Taylor, B.G., Eds., Batterer Intervention Programs: Where Do We Go from Here? NCJ Publication No. 195079, National Institute of Justice, Washington DC, 23-29.

[3] Eisikovits, Z.C. and Edleson, J.L. (1989) Intervening with Men who Batter: A Critical Review of the Literature. Social Service Review, 63, 384-414. http://dx.doi.org/10.1086/603710

[4] Gondolf, E. (1997) Batterer Programs: What We Know and What We Need to Know. Journal of Interpersonal Violence, 12, 83-98. http://dx.doi.org/10.1177/088626097012001006

[5] Rosenfeld, H.D. (1992) Court-Ordered Treatment of Spouse Abuse. Clinical Psychology Review, 12, 205-226. http://dx.doi.org/10.1016/0272-7358(92)90115-O

[6] Tolman, R.M. and Bennett, L.W. (1990) A Review of Quantitative Research on Men Who Batter. Journal of Interpersonal Violence, 5, 87-118. http://dx.doi.org/10.1177/088626090005001007

[7] Babcock, J.C., Green, C.E. and Robie, C. (2004) Does Batterer’s Treatment Work? A Meta-Analytic Review of Domestic Violence Treatment. Clinical Psychology Review, 23, 1023-1053. http://dx.doi.org/10.1016/j.cpr.2002.07.001

[8] Feder, L. and Wilson, D.B. (2005) A Meta-Analytic Review of Court Mandated Batterer Intervention Programs: Can Courts Affect Abuser's Behavior? Journal of Experimental Criminology, 1, 239-262. http://dx.doi.org/10.1007/s11292-005-1179-0

[9] Barnett, O.W. and Planeaux, P.S. (1989) A Hostility-Guilt Assessment of Counseled and Uncounseled Batterers. Paper Presented at the Responses to Family Violence Research Conference, Purdue University, West Lafayette.

[10] Makin-Byrd, K. and Azar, S.T. (2011) Beliefs and Attributions of Partner Violence Perpetrators: The Physical and Psychological Violence of Adolescent Males. Violence and Victims, 26, 177-190. http://dx.doi.org/10.1891/0886-6708.26.2.177

[11] Maiuro, R.D., Cahn, T.S., Vitaliano, P.P., Wagner, B.C. and Zegree, J.B. (1988) Anger, Hostility, and Depression in Violent versus Generalized Assaultive Men and Nonviolent Control Subjects. Journal of Consulting and Clinical Psychology, 56, 17-23. http://dx.doi.org/10.1037/0022-006X.56.1.17

[12] Eckhardt, C.I., Barbour, K.A. and Stuart, G.L. (1997) Anger and Hostility in Martially Violent Men: Conceptual Distinctions, Measurement Issues, and Literature Review. Clinical Psychology Review, 17, 333-358. http://dx.doi.org/10.1016/S0272-7358(96)00003-7

[13] Eckhardt, C.I. and Deffenbacher, J.L. (1995) Diagnosis of Anger Disorders. In: Kassinove, H., Ed., Anger Disorders: 
Definition, Diagnosis, and Treatment, Taylor \& Francis, Washington DC, 27-47.

[14] Tolman, R.M. and Saunders, D. (1988) The Case for the Cautious Use of Anger Control with Men Who Batter. Response, 11, 15-20.

[15] Buss, A.H. (1961) The Psychology of Aggression. Wiley, New York. http://dx.doi.org/10.1037/11160-000

[16] Jin, X., Eagle, M. and Keat, J.E. (2008) Hostile Attributional Bias, Early Abuse, and Social Desirability in Reporting Hostile Attributions among Chinese Immigrant Batterers and Nonviolent Men. Violence and Victims, 23, 773-786.

[17] Speilberger, C.D. (1988) Manual for the State-Trait Anger Expression Inventory. Psychological Assessment Resources, Odessa, FL.

[18] Ainsworth, M.S. (1989) Attachments beyond Infancy. American Psychology, 44, 709-716. http://dx.doi.org/10.1037/0003-066X.44.4.709

[19] White, H.R. and Widom, C.S. (2003) Intimate Partner Violence among Abused and Neglected Children in Young Adulthood: The Mediating Effects of Early Aggression Antisocial Personality, Hostility, and Alcohol Problems. Aggressive Behavior, 29, 332-345. http://dx.doi.org/10.1002/ab.10074

[20] Maiuro, R.D., O’Sullivan, M.J., Michael, M.C. and Vitaliano, P.P. (1989) Journal of Clinical Psychology, 45, $531-541$. http://dx.doi.org/10.1002/1097-4679(198907)45:4<531::AID-JCLP2270450406>3.0.CO;2-K

[21] Barnett, O.W., Fagan, R. and Booker, J.M. (1991) Journal of Family Violence, 6, 217-241. http://dx.doi.org/10.1007/BF00980530

[22] Hershorn, M. and Rosenbaum, A. (1991) Over- vs. Under-Controlled Hostility: Application of the Construct to the Classification of Martially Violent Men. Violence and Victims, 6, 151-158.

[23] Megargee, E.I., Cook, P.E. and Mendelsohn, G.A. (1967) Development and Validation of an MMPI Scale of Assaultiveness in Overcontrolled Individuals. Journal of Abnormal Psychology, 72, 519-528. http://dx.doi.org/10.1037/h0025242

[24] Boyle, D.J. and Vivian, D. (1996) Generalized versus Spouse-Specific Anger/Hostility and Men’s Violence against Intimates. Violence and Victims, 11, 293-317.

[25] Maiuro, R.D., Cahn, T.S. and Vitaliano, P.P. (1986) Assertiveness Deficits and Hostility in Domestically Violent Men. Violence and Victims, 1, 279-289.

[26] Kachadourian, L.K., Homish, G.G., Quigley, B.M. and Leonard, K.E. (2012) Alcohol Expectancies, Alcohol Use, and Hostility as Longitudinal Predictors of Alcohol-Related Aggression. Psychology of Addictive Behaviors, 26, 414-422. http://dx.doi.org/10.1037/a0025842

[27] Holtzworth-Munroe, A. and Hutchinson, G. (1993) Attributing Negative Intent to Wife Behavior: The Attributions of Martially Violent versus Nonviolent Men. Journal of Abnormal Psychology, 102, 206-211. http://dx.doi.org/10.1037/0021-843X.102.2.206

[28] Wallach, H.S. and Sela, T. (2008) The Importance of Male Batter's Attributions in Understanding and Preventing Domestic Violence. Journal of Family Violence, 23, 655-660. http://dx.doi.org/10.1007/s10896-008-9189-0

[29] Holtzworth-Munroe, A. and Stuart, G.L. (1994) Typologies of Male Batterers: Three Subtypes and the Differences among Them. Psychological Bulletin, 116, 476-497. http://dx.doi.org/10.1037/0033-2909.116.3.476

[30] Pence, E. and Paymar, M. (2011) Creating a Process of Change for Men Who Batter: The Duluth Curriculum. Domestic Abuse Intervention Programs, Duluth.

[31] Check, J.V.P. (1984) The Hostility toward Women Scale. Unpublished Doctoral Dissertation, University of Manitoba, Winnipeg.

[32] Marshall, W.L. and Moulden, H. (2001) Hostility toward Women and Victim Empathy in Rapists. Sex Abuse, 13, 249255. http://dx.doi.org/10.1177/107906320101300403

[33] Buss, A.H. and Perry, M. (1992) The Aggression Questionnaire. Journal of Personality and Social Psychology, 63, 452-459. http://dx.doi.org/10.1037/0022-3514.63.3.452

[34] Pence, E. and Paymar, M. (1993) Education Groups for Men Who Batter: The Duluth Model. Springer Publishing Company, New York. 